
\title{
3 Research Square \\ The Consequences of methamphetamine regular use in Tehran: qualitative content analysis
}

Javad Yoosefi Lebni

Iran University of Medical Sciences School of Behavioral Sciences and Mental Health

Arash Ziapour

Kermanshah University of Medical Sciences

Mostafa Qorbani

Alborz University of Medical Sciences

Fereshteh Baygi

Aalborg University Esbjerg

Amin Mirzaei

Ilam University of Medical Sciences

Omid Safari

Alborz University of Medical Sciences

Babk Rastegarimehr

Abadan University of Medical Sciences

Bahar Khosravi

Azarbaijan Shahid Madani University Faculty of Basic Sciences

Morteza Mansourian ( $\square$ mansourian55@gmail.com )

Tehran University of Medical Sciences https://orcid.org/0000-0002-2482-5424

\section{Research}

Keywords: Methamphetamine, Regular users, Consequences, Qualitative study, Tehran

Posted Date: March 30th, 2020

DOI: https://doi.org/10.21203/rs.2.19828/v2

License: (c) (1) This work is licensed under a Creative Commons Attribution 4.0 International License.

Read Full License 


\section{Abstract}

Background: In recent years, methamphetamine regular use has increased noticeably in Iran, and this can have harmful consequences for the health of individuals and society. Therefore, the aim of this study is to investigate the consequences of methamphetamine regular use in Tehran.

Methods: This qualitative content analysis study was carried out by using conventional approach. Date were collected through observation and in-depth interview with 20 regular users of methamphetamine adult in Tehran ( 15 males and 5 female). Participants were selected through snowball and purposeful sampling method which continued until data saturation. Guba and Lincoln criteria were used to assess the strength of the research.

Results: The extraction of the codes resulted in three main categories, including: 1. The short-term consequences, consisting of the sub-categories of individual and social consequences 2 . The long-term consequences, consisting of the sub-categories of psychological and physical consequences, high risk behaviors, severely decayed memory and changes in the eating pattern. 3. hallucinations and delusions including the sub-categories of visual and auditory hallucinations, delusion of suspicion and delusion of having supernatural power.

Conclusion: Methamphetamine regular use has serious adverse effects on overall health of individuals. Therefore, implementing educational programs in order to raise awareness and changing attitudes about the short and long term consequences of using methamphetamine in high risk group is highly recommended.

\section{Background}

Drug use is one of the most controversial issues in the field of social sciences [1,2], and dependence on it is recognized as a illness, as well as a sociopolitical and health problem worldwide [3]. Recently in Iran, consumption pattern of drugs has changed so that young generation who are willing to consume drugs are seeking new ones such as methamphetamine, crack and heroin [4,5]. Methamphetamine is one of the stimulant drugs [6], which has become popular in Iran with the name of crystal and is one of the most misused substances and its prevalence in Iran is $5.2 \%$ of consumers [7]. Insurance companies are reluctant to pay the costs when they detect a psychiatric problem due to drug usage. So, underreporting of drug consumption is a real problem [8-10]. The growth of methamphetamine consumption in the world [11] and Iran has become as an important problem for the health sector [12-14] at the individual and social levels $[15,16]$.

Easiness of producing with uncommon compounds and different degree of purity, low cost and high income, easy availability, simple and little needed equipment, possibility of mass production, and difficulty in identifying laboratories make its trade very lucrative [17]. Although it can cause a lot of 
dangers, such as explosion, burns, lung burns and even cancer, for manufacturers and those who are near the places of production and exposed to waste[18-20].

The regular use of methamphetamine can have lifelong dangerous effects [21]. The results of Ahmad Hatim's 2011 research on methamphetamine dependence in Malaysia showed that the prevalence of psychiatric co-morbidity among these people was $54.4 \%$ and the prevalence of suicide was $12.1 \% .47 .9 \%$ of these people had high levels of methamphetamine-induced psychosis [15].

In 2012, Petit et al, found a significant association between methamphetamine addiction and personality disorders, cardiovascular, pulmonary, infectious and dental [11]. Sommers et al. in a study entitled Methamphetamine use among young adults: health and social consequences showed that the methamphetamine regular use was associated with consequences such as weight loss, seizures, and epilepsy. In addition, many methamphetamine abusers experienced severe psychological symptoms or diseases such as depression, hallucinations, paranoia, and violence [22]. Also In a systematic review of Marshall and Warb, there was a strong association between methamphetamine use and increased depression, psychosis and suicide mortality risk, but no association was found between methamphetamine use and infectious and dental diseases [23, 24].

The abuse of methamphetamine creates a sense of euphoria and lightness in a person and is highly addictive. Methamphetamine rapidly enters the brain after taking and causes sudden secretion of neurotransmitters including norepinephrine, dopamine and serotonin. The most important consequences of the use of this substance include obsessive-compulsive disorder [25], fetishism [26], depression [27], antisocial behavior [28, 29], violent behavior [30], movement disorders like Parkinson's disease [31], low mental health [32], insomnia [33], and risky sexual behavior [34].

Although many studies have been done on the side effects of methamphetamine throughout the world, most of them have been carried out quantitatively and experimentally. Crystal meth is produced in more different conditions in Iran [35]. Therefore, it has effects different from those of drugs produced in other countries. Also, since qualitative studies provide better understanding of phenomena and can explain human beings' life experiences, interpretations and perceptions in the cultural and social context that they occurred [36,37], there is a need for qualitative research in this field. Therefore, this study was conducted with a qualitative content analysis approach and with the aim of exploring the consequences of methamphetamine regular use in Tehran.

\section{Methods}

\section{Design and sample}

This research was conducted using qualitative approach and conventional qualitative content analysis. Qualitative content analysis is one of the qualitative research approaches for analyzing text data and is, in fact, a systematic classification and coding technique aimed at better understanding of the phenomenon under study [38]. 
The study population consisted of methamphetamine regular users in Tehran who had a history of at least three months persistent methamphetamine use and had not previously experienced use another drug. In-depth interview and observation were used to collect data. In fact, the first author of the paper only observed and noted the behaviors and physical symptoms of the methamphetamine regular user as a roommate without any intervention. Interviews were conducted by the first and eighth authors.

Considering that one of the authors) first author (of this article experienced living with a methamphetamine regular user as a roommate for 5 months, the observations of the author were coded and analyzed to record the behavior of that person. The criteria to enter the study included methamphetamine regular use at the time of study, experience of at least three months methamphetamine regular use, no history of psychiatric disorder before methamphetamine regular use, not being addicted to other drugs at the time of the study and before it, and the willingness to participate in research. Regarding the subject of the research and the difficulty of samples identification, snowball and purposeful sampling was used.

\section{Data collection and analysis}

Accordingly interviews were conducted with methamphetamine regular users in Tehran until data saturation was reached. Data saturation occurred with interviews with 20 people including 15 men and 5 women. When the code obtained from the interviews is repeated and the researcher ensures that no new codes are formed by continuing the interview, the theoretical saturation will result and the researcher can interrupt the interview process because new information will not be obtained by continuing the interview [39].The duration of the interview was adjusted according to the willingness of the participant to answer the questions, which took an average of 40 minutes.

At the beginning of each interview, demographic questions were asked and then the interview continued with questions like How did you feel about the first time you methamphetamine use? What changes have occurred in your body, personality and personal and social behaviors due to short-term methamphetamine regular use (during the first six months)? What interesting things did you experience that you felt didn't happen to others during methamphetamine regular use? Explain the hallucinations you experienced after methamphetamine regular use. During the interviews full attention was paid to the appearance and body language of the participants for more comprehensive information. After each interview, the data was coded and analyzed.

After encoding and summarizing the data based on similarities and differences, the classification of codes was performed and the classes were compared together and ultimately, themes were extracted by the analysis and interpretation of these data. Graneheim and Lundman method was used to analyze the data [38]. In the first step, the whole content of the interview was transcribed word by word and read several times until a general concept of the text was obtained. Then the text was divided into independent concepts and marked with specific codes. In the next step, the codes were divided into subcategories and classified according to similarities and differences. Finally, the hidden content was found and reported. an example of analysis and coding is given in Table 1 (Table 1). 
Table 1 An example of code analysis

\begin{tabular}{|l|l|l|l|}
\hline Categories & Subcategories & Codes & Quotes \\
\hline $\begin{array}{l}\text { Short-term } \\
\text { consequences }\end{array}$ & $\begin{array}{l}\text { Individual } \\
\text { consequences }\end{array}$ & $\begin{array}{l}\text { enhancing } \\
\text { sexual } \\
\text { ability }\end{array}$ & $\begin{array}{l}\text { "The first month I was using crystal my sexual power was very good, I } \\
\text { was pleased with myself." }\end{array}$ \\
\cline { 2 - 4 } & $\begin{array}{l}\text { Social } \\
\text { consequences }\end{array}$ & $\begin{array}{l}\text { Getting } \\
\text { more } \\
\text { social }\end{array}$ & $\begin{array}{l}\text { "I was always an aloof person. My family always kept on at me about } \\
\text { being isolated, but since I used crystal, I was not like that anymore, I } \\
\text { got so socialized, and my family is pleased with me." }\end{array}$ \\
\hline
\end{tabular}

Guba and Lincoln criteria were used to assess the accuracy and rigor of the present study [40]. As to credibility of the data, the author had a prolonged engagement with the participants to win their trust and have a better perception of their experiences. In addition, the coding and analyses results were forwarded to some of the participants to check if the results reflect their opinions and viewpoints (member check). To consider the transferability of data, the obtained information was examined and approved by three specialists who are experts in the field of qualitative research and methamphetamine studies. In fact, the process of coding and analyzing the data was sent to them and their comments were used to name the categories and sub-categories. Also a comprehensive description of the subject was provided and direct quotes from participants were used.

\section{Ethics}

In this study, ethical considerations were made in accordance with the Helsinki Declaration. This study was approved by the Ethics Committee of Iran University of Medical Sciences. All subjects were informed about the study and all provided informed consent. There was emphasis on maintaining privacy and respecting the honesty in keeping and delivering the information accurately without mentioning the names of the people. Subsequently, participants were given the right to leave the interview at any time, if they wished to leave the interview process, and they were promised to have the study results if they want.

\section{Results}

\section{Sample characteristics}

The results showed that the average age of the samples was $27 \pm 7.36$ years and the average duration of their drug use was $25 \pm 25.41$ months. Also, the majority of the sample were single, male and had bachelor's degree (Table 2).

Table 2 Demographic information of sample 


\begin{tabular}{rrrrrr}
\hline NO & Age & Gender & Duration of drug use & Level of Education & Marriage status \\
\hline 1 & 25 & Male & 1 year & Bachelor's degree & Married \\
2 & 22 & Male & 9 months & High school diploma & Single \\
3 & 28 & Male & 2 years & Bachelor's degree & Single \\
4 & 33 & Male & 3 years & High school diploma & Married \\
5 & 18 & Male & 6 months & High school diploma & Single \\
6 & 30 & Male & 4 years & Bachelor's degree & Married \\
7 & 20 & Male & 1 year & High school diploma & Single \\
8 & 24 & Male & 1 year & Unfinished high school & Single \\
9 & 28 & Male & 9 months & Bachelor's degree & Single \\
10 & 32 & Male & 3 years & Unfinished high school & Single \\
11 & 29 & Male & 2 years & Bachelor's degree & Single \\
12 & 49 & Male & 10 years & Unfinished high school & Married \\
13 & 33 & Male & 1 year & Master's degree & Single \\
14 & 35 & Male & 3 years & Master's degree & Married \\
15 & 19 & Male & 10 months & High school diploma & Single \\
16 & 23 & Female & 1 year & High school diploma & Single \\
17 & 21 & Female & 2 years & Bachelor's degree & Single \\
18 & 28 & Female & 3 years & Bachelor's degree & Married \\
19 & 18 & Female & 8 months & Unfinished high school & Single \\
20 & 25 & Female & 2 years & Bachelor's degree & Married \\
\hline
\end{tabular}

After analyzing data, three main categories were identified which are presented in table 3: 1 . Short-term consequences consisting of individual and social consequences. 2. Long-term consequences consisting of physical, psychological and behavioral consequences and decayed memory. 3. Illusions consisting of visual and auditory illusions. Then quotes and other explanations are given.

Table 3 Categories, subcategories and codes 


\begin{tabular}{|c|c|c|}
\hline Categories & Subcategories & Codes \\
\hline \multirow[t]{2}{*}{$\begin{array}{l}\text { Short-term } \\
\text { consequences }\end{array}$} & $\begin{array}{l}\text { Individual } \\
\text { consequences }\end{array}$ & $\begin{array}{l}\text { Getting euphoric, getting happier, getting stronger, getting more focused, } \\
\text { enhancing sexual ability }\end{array}$ \\
\hline & $\begin{array}{l}\text { Social } \\
\text { consequences }\end{array}$ & $\begin{array}{l}\text { Getting more social, more acceptance in the society, family happiness after the } \\
\text { first months of drug use }\end{array}$ \\
\hline \multirow[t]{5}{*}{$\begin{array}{l}\text { Long-term } \\
\text { consequences }\end{array}$} & $\begin{array}{l}\text { Physical } \\
\text { consequences }\end{array}$ & $\begin{array}{l}\text { Decayed and broken teeth, dry mouth, sunken eyes, many wounds on the body } \\
\text { especially hands, wounded gums, many pimples (under or over the skin) on the } \\
\text { face and chin, sleep decrease, having a noisy sleep, pain and burning of the } \\
\text { throat, getting thin. }\end{array}$ \\
\hline & $\begin{array}{l}\text { Psychological } \\
\text { consequences }\end{array}$ & $\begin{array}{l}\text { Depression, having irrational beliefs about associates, thinking about suicide, } \\
\text { getting insouciant about everything, Obsessive Compulsive Disorder (OCD) }\end{array}$ \\
\hline & $\begin{array}{l}\text { high risk } \\
\text { behaviors }\end{array}$ & $\begin{array}{l}\text { Doing dangerous activities like high-speed driving, committing suicide, fighting a } \\
\text { lot, mistreating the spouse, loss of control of behavior, high levels of violence } \\
\text { against associates, wounding their bodies, having sex with multiple people, } \\
\text { decrease of sexual power, getting rougher in sex, Jumping from high altitude due } \\
\text { to lack of correct distance detection, excessive talking, excessive anger. }\end{array}$ \\
\hline & $\begin{array}{l}\text { Highly } \\
\text { decayed } \\
\text { memory }\end{array}$ & $\begin{array}{l}\text { Forgetting words while talking, forgetting the names of relatives, breaking the } \\
\text { promise, keeping on at something, missing the addresses many times, losing } \\
\text { different things like keys, forgetting the password of bank card, lack of focus. }\end{array}$ \\
\hline & $\begin{array}{l}\text { Changes in } \\
\text { eating pattern }\end{array}$ & $\begin{array}{l}\text { Excessive consumption of drinks specifically soft drink, lack of tendency to } \\
\text { consume sour things like yogurt drink, tendency to overeat sweats, lack of balance } \\
\text { in eating, eating less }\end{array}$ \\
\hline \multirow[t]{4}{*}{$\begin{array}{l}\text { Hallucinations } \\
\text { and delusions }\end{array}$} & $\begin{array}{l}\text { Visual } \\
\text { Hallucinations }\end{array}$ & $\begin{array}{l}\text { Seeing strange things, seeing things other than their face in the mirror, the } \\
\text { illusion of believing in things that are not real, the illusion of living with imaginary } \\
\text { people, having horns on the head in the mirror, seeing someone sitting next to bed } \\
\text { at night, seeing a little girl with long hair, illusion of seeing the elephant while } \\
\text { driving, seeing trees as police officers, illusion of seeing the sea and the ship, } \\
\text { illusions of hitting people by car (while they hit a cat), seeing small ants on the } \\
\text { arm, claiming to see things that others cannot see, and the illusion of attending a } \\
\text { big concert }\end{array}$ \\
\hline & $\begin{array}{l}\text { Auditory } \\
\text { Hallucinations }\end{array}$ & $\begin{array}{l}\text { To hear the result of football game before it starts, to hear a voice encouraging the } \\
\text { person to commit suicide, to hear the sound of walking feet in the sleep, to hear } \\
\text { strange noises }\end{array}$ \\
\hline & $\begin{array}{l}\text { delusion of } \\
\text { suspicion }\end{array}$ & $\begin{array}{l}\text { Conspiracy of colleagues to kill them, suspicion about spouse's betrayal, suspicion } \\
\text { about neighbors for the desire to kill them, the illusion of being chased by } \\
\text { anonymous people, the illusion of an individual coming to the room and moving the } \\
\text { thing, the illusion of being harmed by others and the illusion of cameras being in } \\
\text { the houses they rented. }\end{array}$ \\
\hline & $\begin{array}{l}\text { delusion of } \\
\text { having } \\
\text { supernatural } \\
\text { power }\end{array}$ & $\begin{array}{l}\text { Believing in having the perfect sixth sense and the illusion of predicting } \\
\text { everything (like results of soccer games) }\end{array}$ \\
\hline
\end{tabular}

1. Short-term consequences: methamphetamine regular use initially has associated with positive outcomes, such as increased concentration and sexual ability, but these positive outcomes are not sustainable, and after some time these positive effects are replaced by negative outcomes, such as hallucinations and so on.

consequences that appear to be beneficial which make it more satisfactory to the person, but they are not sustainable. 
1-1 Individual consequences: methamphetamine regular use initially causes physical and psychological changes in an individual that can affect his or her behavior, and in some cases, these behaviors are appealing to a person.

Participant No. 7 said: "I got much more focused at the beginning of using crystal. I studied less, but I learned more and my grades were much better, I was very pleased with myself."

Participant No. 1 said: "The first month I was using crystal my sexual power was very good, I was pleased with myself." Participant No. 11 also said: "when I started to use crystal, I got stronger and I lifted weights more than ever."

1-2 Social consequences: The consumption of methamphetamine in the short term creates selfconfidence in the person, and this causes the person's social behavior to change. Unfortunately, one of the features of methamphetamine is that it has positive effects in the early short-term period, which cause not to detect bad effects in a short period of time.

Participant No. 2 said: "I was always an aloof person. My family always kept on at me about being isolated, but since I used crystal, I was not like that anymore, I got so socialized, and my family is pleased with me."

Participant No. 9 said: "I was afraid of being in the crowd. I did not like to be in parties. If I went, I sat quietly and do not say anything. But after starting using crystal, I felt more confident, I talk more in parties and I like more to be with people."

2- Long-term consequences of methamphetamine consumption: long-term consequences of methamphetamine consumption are far more destructive than those of other substances, both in terms of physical and psychological consequences of this substance and. In fact, after a relatively short period of initial consumption, its harmful effects are observed which may lead to harm to the regular user themselves or their family or even the society and completely disturb the life of the user.

2-1 Physical consequences: The effects of methamphetamine consumption in the long period of time cause changes in the body of regular users, which can disrupt their life and endanger the health of the individual.

Participant No. 12 said: "My body always itches; sometimes I scratch my skin so much that it gets wounded and bleeds". Participant No. 10 also said: "All my teeth are rotten. I can hardly eat anything, whenever I eat my gums bleed".

Participant No. 4 also said: "I cannot sleep like before, my sleep is messed up; sometimes I cannot sleep at all."

2-2 Psychological Consequences: Methamphetamine regular use causes mental changes in regular user which can disrupt his life. 
Participant No. 18 said: "After a while using crystal, I got insouciant about everything, I do not care about anything. Nothing makes me happy or sad." Participant No. 20 said: "for a while, I think of suicide all the time. I think about how to kill myself." Participant No. 8 said: "I've been very obsessive-compulsive recently. When I want to do something I think about it so much that I cannot really do it and its time passes."

2-3 high risk behaviors: Long-term consumption of methamphetamine causes regular user to show unpredictable behaviors that can endanger their own lives and others' lives, and may cause death to themselves or their associates.

Participant No. 6 said: "Recently, I've been fighting all the time. I beat my wife. I fight with my in-law family. I keep on at everyone."

Participant No. 10 said: "I have sex with many people, although I know it can be dangerous, I do it again." Participant No. 4 said: "I speak angrily to my wife every day; sometimes I beat her so much that I fear that she will die."

2-4 Highly decayed memory: Long-term consumption of methamphetamine leads to memory decay, so that the person faces difficulty in doing daily routine activities.

Participant No. 8 said: "I forget my friends' names; I even confuse the names of my family members."

Participant No. 12 said: "I got very forgetful lately; I forget my password and give the wrong one."

Participant No 6 said: "Sometimes I miss my home address even though we have been living there for ten years."

Participant No. 12 said: "Sometimes it happens that I get myself busy doing something. Then I look at the clock and see that I only sit down for eight or nine hours getting busy with that idle thing."

2-5 Changes in eating pattern: Long-term consumption of methamphetamine causes changes in nutrition patterns of eating and may lead to a tendency towards foods or drinks that were not consumed by them before.

Participant No. 20 said: "I used to love sour things a lot before, but since I started using crystal I do not like them, I'd love to eat sweet things and drink very much, too." Participant No. 19 said: "Since I started using crystal, my appetite has decreased and I've been eating too little." Participant No. 13 said: "My eating is not balanced. I sometimes eat so much that my family get worried. Sometimes it happens that I do not have anything for two days."

3- Common hallucinations and delusions Caused by consumption of methamphetamine: One of the common consequences of methamphetamine consumption is the creation of hallucinations and delusions in people, which sometimes causes violence against themselves and others, and may even result in murder and suicide. 
3-1 Visual hallucination: Methamphetamine consumption causes visual hallucinations in regular users, such as claiming to see things that others cannot see.

Participant No 3 said: "In an evening that I was driving, I hit a cat with my car, but I thought I hit a person. For a while I felt I was being chased. I hid myself."

Participant No. 10 said: "Sometimes I see tiny ants that march on my arm, so I scratch my arm until they all die."

Participant No. 16 said: "At night, a little girl comes and sits next to my bed, I say to my family, but they say there is nothing."

3-2 Auditory hallucinations: Methamphetamine consumption also results in auditory hallucinations, as many methamphetamine consumers claim to be able to hear voices that others cannot hear.

Participant No. 17 said: "Sometimes a voice keeps on at me that I should kill myself. I tried to kill myself a few times, but my family did not let me." Participant No. 3 said: "When I sleep, I hear feet that come close to me, but as I open my eyes, I see nobody. But when I close my eyes again, I hear the feet."

3-3 delusion of suspicion: Another problem that appears with the regular use of methamphetamine is the delusion of suspicion. It makes a person pessimistic about others and may lead to violence against them.

Participant No 12 said: "I always felt that my wife was betraying me, so I did not let her go out and she was always under my watch, this caused us to fight, and I always beat her."

Participant No. 10 said: "I always feel that my colleagues want to kill me, once the butler wanted to put poison in my tea, but I understood it." Participant No. 7 said: "I feel like everyone wants me to die, they all want to kill me."

3-4 delusion of having supernatural power: Methamphetamine consumption in some cases causes a person to claim to have supernatural powers and have an delusion of being associated with the universe.

Participant No. 9 said: "My sixth sense is perfect, and I can predict everything even results of football matches, someone comes to me before the game starts and tells me the result of the game."

Participant No. 11 said: "I can predict the upcoming events, I can even figure out who is about to die."

\section{Discussion}

This study aimed to exploring the consequences of methamphetamine regular use in Tehran. The results showed that methamphetamine consumption in the short period of time is accompanied by individual consequences such as being happier, increased confidence, increased concentration and improved sexual power and social consequences such as getting more sociable, etc., which can lead to more desire to continue consumption. This is in line with Kennedy (2015) [41], Bustani and Karamizadeh [42], Mohib Ali 
and colleagues [43], Sia Johnny et al [44]. . But over time, As showed at the result section this study, positive outcomes are gradually replaced by negative outcomes.

In Baangy et al, insomnia [32] and in Shakiba et al, increase of excitement and concentration [13] has been mentioned as short-term consequences of methamphetamine consumption.

Positive short-term consequences of methamphetamine may cause the family to be more pleased with the individual, and this encourages the person to continue. Since the families are more satisfied with the change in the person's behavior, they have less doubt that perhaps this change in behavior is due to methamphetamine consumption. But the regular use of methamphetamine in the long run is accompanied by extremely dangerous consequences for the individual and even the society, which can disrupt the life of the individual and society.

According to the findings of this study, the physical and psychological consequences, high risk behaviors , decayed memory and changes in the pattern of eating were among the sub-categories related to the long-term consequences of methamphetamine consumption. The results showed that long-term consumption of the methamphetamine would affect human body and could have harmful effects on it, endangering the health of the individual and even leading to their death. Previous studies reported the association between methamphetamine regular use and human physical health; for example, the relationship between the methamphetamine abuse and oral dryness(dry mouth), cardiovascular diseases [45], infectious diseases such as endocarditis [46] and teeth decay $[47,48]$ has been proven in previous studies in this area.

Psychological consequences such as depression, having irrational beliefs about associates, thinking about suicide, insouciance about everything and obsessive-compulsive disorder are other long-term effects of methamphetamine consumption in this study. The results of previous studies showed that the abuse of methamphetamine is associated with the sustainable psychological changes in regular users, such as depression, isolation, personal conflicts [49], irrational thoughts [50], and obsessive compulsive disorder [28].

Another sub-category related to long-term consequences was high risk behaviors. Long-term consumption of the methamphetamine can change the person's behavior and increase the high-risk behaviors [51]. Changes in behavior and an increase in risky behaviors are the symptoms of long-term regular use of methamphetamine. Violence, aggressiveness, and hostile attitudes are also common in methamphetamine users.[52,53]. Also, regular using methamphetamine can increase the sexual need of an individual abnormally, and because of the other effects of this substance, it causes incontinence in a person, so that he no longer uses preventive measures and devices. And the person is forced to indulge in sexual activity with multiple people that can endanger the health of the individual and lead to AIDS, hepatitis and other sexually transmitted diseases [54-58] .

Another symptom of long-term regular use of the methamphetamine is memory disorder. Maxwell (2005) and Lundqvist (2005) found a significant relationship between the methamphetamine abuse and the 
decreased cognitive and psychosocial functioning in the individual $[58,59]$ and caused problems such as memory decrease, confusion, and forgetfulness $[60,61]$ Continued use can also result in memory loss, and people with it resemble those who have Alzheimer's disease [62].

Changes in the pattern of eating are another sub-category of long-term consequences which was a new findings that is not mentioned in other studies. Changes in eating pattern and excessive loss of appetite have to do with using methamphetamine so that the regular users lose weight and suffer malnutrition after a while. [63]. However, this consequence of methamphetamine consumption may be attractive for some. Maybe one of the main reasons of tendency to methamphetamine, especially for women, is their decision for weight loss. As shown in previous studies, the women who consume methamphetamine weight significantly less than the women who do not use it [64].

Another consequence of the regular use of methamphetamine is the hallucination and delusion in the user person which is not mentioned by previous studies. These hallucinations and delusions sometimes lead to social harm and murder, which unfortunately we see a title related to this issue (e.g. Crystal user Killed his Family) in the newspapers every day, and it increases day by day due to increasing the number of methamphetamine consumers. The common visual hallucinations that these people have include seeing things without real existence and no one else can see these things except them. In some cases, users have the hallucination of seeing insects on their skin, which results in scratching and wounding their skin, which is why many people who are use this drug usually have a lot of wounds $[23,65]$. In the studies of Baggott et al and Akiyama, visual hallucinations caused by methamphetamine use were also reported $[66,67]$.

Auditory hallucinations also are observed in them, some of which sometimes stimulate the regular users to hurt themselves and others. Auditory hallucinations were also reported in methamphetaminedependent in the study of Mahoney et al [68].

Another form of hallucinations and delusions that these people have is the delusion of having supernatural power, so that they think they have extra-human power and can fight the whole world; in fact, it creates a kind of false self-confidence in them. The majority of methamphetamine regular users believed they have superhuman strength to do extraordinary things, such as predicting the future, and because these people saw themselves as safe in danger, they took dangerous actions and endangered their health.

But perhaps the worst kind of delusions that these people have is the delusion of others' conspiracy against them [25]. In fact, many methamphetamine regular users experience this delusion that others are thinking about harming him or that their wife or husband plans to betray them. This type ofdelusion makes these people commit dangerous unpredictable behaviors. One of the new results in this study, not mentioned in previous studies, may be due to differences in the composition of methamphetamine made in Iran of different compounds and having different effects. Sometimes severity of these behaviors can be highly bothering for the society. The study of Mansourian and his colleagues also showed that methamphetamine users have suspicion about associates [65]. 


\section{Strengths and Limitations}

The present study is the first Iranian research that addresses the consequences of methamphetamine regular use in Tehran, the capital city of Iran, through a qualitative approach since first-hand information can be attained by doing so. Moreover, given that the first author of the present study himself had the experience of living with a methamphetamine regular user previously, the real behaviors of methamphetamine regular users could be identified and recorded easily to some extent. Another strength of the study was the selection of subjects with no previous use any other drugs except methamphetamine, which per se could be helpful in discovering the specific consequences of methamphetamine regular use. However, there were some limitations, too. One of the main limitations was the difficulty of access to methamphetamine regular users, which was resolved through choosing an appropriate sampling method and drawing the trust of the samples to introduce their peer users friends. Another problem was determining the time and place of the interview, which was repeatedly changed by participants, which was then solved by the researchers through repeated visits to the place of the interview.

\section{Conclusion}

The harmful consequences of methamphetamine consumption can endanger the health of the individual, family and society. Therefore, raising the knowledge about the short- and long-term effects of methamphetamine regular use and its symptoms as well as providing appropriate programs to change attitudes toward the consequences of methamphetamine regular use can be an effective step in preventing the use of this drug. In addition, appropriate counseling to methamphetamine regular users and assisting their rehabilitation to return to a healthy life are recommended to control the adverse effects caused by the use of this drug.

\section{Abbreviations}

MH: Methamphetamine use; QCA: Qualitative Content Analysis

\section{Declarations}

Acknowledgements

All participants in this study are appreciated.

Authors' contributions

All authors have made contributions to the paper and authorized submission.

Javad Yoosefi lebni, Fereshteh Baygi, Arash Ziapour, Morteza Mansourian: Conception of study design, data analysis support, interpretation, drafting of article and approved final manuscript as submitted. 
Javad Yoosefi lebni, Arash Ziapour, Bahar Khosravi, Mostafa Qorbani: Data analysis, interpretation, drafting of article, revisions and approved final manuscript as submitted.

Amin Mirzaei, Omid Safari, Babk Rastegarimehr, Morteza Mansourian: Interpretation, critical review and revisions, approved final manuscript as submitted.

Funding

No external funding sources were provided for this study.

Availability of data and materials

The datasets generated and analyzed during the current study are not

Publicly available due to protect the participants' anonymity but are

Available from the corresponding author on reasonable request.

Author details

Ethical Approval and consent to participate

Ethics The study procedures were carried out in accordance with the Declaration of Helsinki. This study was approved by the Ethics Committee of Iran University of Medical Sciences. All subjects were informed about the study and all provided informed consent. There was emphasis on maintaining privacy and respecting the honesty in keeping and delivering the information accurately without mentioning the names of the people. Subsequently, participants were given the right to leave the interview at any time, if they wished to leave the interview process, and they were promised to have the study results if they want.

Consent for publication

Not applicable.

Competing interests

The authors declare that they have no competing interests.

Author details

1PhD. Candidate. Health Education and Health Promotion, School of Health, Iran University of Medical Sciences, Tehran, Iran, Health Promotion Research Center, Iran University of Medical Sciences, Tehran, Iran. 2Ph.D Student. Health Education and Health Promotion, Health Institute, Kermanshah University of Medical Sciences, Kermanshah, Iran. 3Non-Communicable Diseases Research Center, Alborz University of Medical Sciences, Karaj, Iran and Chronic Diseases Research Center, Endocrinology and Metabolism Population Sciences Institute, Tehran University of Medical Sciences, Tehran, Iran. 4Center of Maritime 
Health and Society, Institute of Public Health, University of Southern Denmark, Esbjerg, Denmark. 5PhD. Public Health Department, Ilam University of Medical Sciences, Ilam, Iran. 6Departments of Pediatrics, School of Medicine, Alborz University of Medical Sciences, Karaj, Iran. 7MSc, Abadan School of Medical Sciences, Abadan, Iran. 8Master of Women Studies, Shahid Madani University of Azerbaijan, Azerbaijan, Iran. 9Health Management and Economics Research Center, Iran University of Medical Sciences, Tehran, Iran.

\section{References}

1. Mansourian M, Abbas J, Qorbani M, Mehr BR, Ziapour A, Lebni JY, et al. Secrecy in Drug Abusers: A Qualitative Study in Iran. J Postgrad Med Institut.33(3):256-61.

2. Pelloux Y, Giorla E, Montanari C, Baunez C. Social modulation of drug use and drug addiction. Neuropharm. 2019.

3. Singer M. Drugs and development: the global impact of drug use and trafficking on social and economic development. Int J Drug Policy. 2008;19(6):467-78.

4. Sajjadi M, Shariatifar N, Matlabi M, Abbasnezhad A, Basiri K, Nazemi H. The rate of knowledge and attitude toward psychoactive drugs and its abuse prevalence in Gonabad University students. Horizon Med Sci. 2009;15(2):58-64.

5. Rezaei F, Noroozi A, Armoon B, Farhoudian A, Massah O, Sharifi H, et al. Social determinants and hepatitis $\mathrm{C}$ among people who inject drugs in Kermanshah, Iran: Socioeconomic status, homelessness, and sufficient syringe coverage. J Subs Use. 2017;22(5):474-8.

6. Dehghan M, Fazel A, Rezaee AM. Effectiveness of psychotherapy with matrix pattern on the glass drug craving. Indian J Health Wellbe. 2017;8(2):113-9.

7. Zolfegharzadeh KM, Khalilzadeh MA, Ghoshooni M, Hashemian P. on the effectiveness of alphatheta neurofeedback in craving for drug use among methamphetamine-dependent patients. 2016.

8. Akhteyari H. Addiction to Glass. Addic Med. 2013;1(2):9-12.

9. Jalali A, Yekzaman M, Bazrafshan M-R, Salari N, Rahmati M. Investigating the effect of family counseling on the acceptance and support of patients under methadone maintenance treatment. Shiraz Med J. 2018;19(5): e62347.

10. Shojaezadeh D, Peyman N, Shakeri MT, Nedjat S, Hakkak AM, Taghdisi MH, et al. Pictorial health warning labels on cigarette packages: An investigation on opinions of male smokers. Iran Red Crescent Med J. 2014;16(3): e14879.

11. Petit A, Karila L, Chalmin F, Lejoyeux M. Methamphetamine addiction: a review of the literature. $J$ Addic Res Therapy. 2012;1.

12. Nouri Khajavi M, Afghah S, Azizi-khoei A. Self-Injury Due to Methamphetamine Psychosis: A Case Report. Iran Rehabilit J. 2015;13(1):77-4.

13. Shakiba M, Shakiba J, Sharifi H, Shakiba M, Rafaiee R. The Effect of Life Skills Training in Group and Behavior Change on Affective Health of People Addicted to Methamphetamine Crystal. Zahedan J 
Res Med Sci. 2014;16(5):6-10.

14. Barr AM, Noroozi A. Methamphetamine-associated psychosis: a new health challenge in Iran. BioMed Central; 2013.

15. Ahmad Hatim S. Methamphetamine dependence in Malaysia: psychiatric co-morbidity and suicidality, methamphetamine induced psychosis, genetic polymorphisms and efficacy of aripiprazole in the treatment of methamphetamine dependence/Ahmad Hatim Sulaiman: University of Malaya; 2011.

16. Hakkak HRM, Taghdisi MH, Shojaezadeh D, Nedjat S, Peyman N, Taghipour A. Clarifying the Role of Schools in Tendency or Lack of Tendency Toward Smoking among Teenage Boys (11-14) in Mashhad, Iran. Iran Red Crescent Med J. 2014;16(1): e12848.

17. Kiani M, Shamloo B, Sadeghi A. Prevention of Psychotropic Substance Use by Adolescents. Med J Q. 2011;5(19):127-67.

18. Ciccarone D. Stimulant abuse: pharmacology, cocaine, methamphetamine, treatment, attempts at pharmacotherapy. Primary Care: Clin Office Pract. 2011;38(1):41-58.

19. Bloom GR, Suhail F, Hopkins-Price P, Sood A. Acute anhydrous ammonia injury from accidents during illicit methamphetamine production. Burns. 2008;34(5):713-8.

20. Davidson SB, Blostein PA, Walsh J, Maltz SB, Elian A, VandenBerg SL. Resurgence of methamphetamine related burns and injuries: a follow-up study. Burns. 2013;39(1):119-25.

21. Anderson K. A Model Program for Treating Methamphetamine Use among Adolescents: Alliant International University; 2018.

22. Sommers I, Baskin D, Baskin-Sommers A. Methamphetamine use among young adults: health and social consequences. Addict behav. 2006;31(8):1469-76.

23. Marshall BD, Werb D. Health outcomes associated with methamphetamine use among young people: a systematic review. Addict. 2010;105(6):991-1002.

24. Farnia V, Alikhani M, Davarinejad O, Golshani S, Salemi S, Hookari S, et al. A discriminant analysis of psychological and brain-behavioural system features to predict methamphetamine dependence. NeuroQuant. 2019;17(8):24-32.

25. Shoaa Kazemi M. The Relationship between Emotional Intelligence and Recurrence of Glass Consumer Consumers in Tehran. Soc Res Q. 2011; 10:137-51.

26. Mehdizadeh-Zareanari A, Ghafarinezhad A, Soltani H. Fetishism due to methamphetamine (glass) abuse: a case report. Addict Health. 2013;5(1-2):73.

27. Brière FN, Fallu J-S, Janosz M, Pagani LS. Prospective associations between meth/amphetamine (speed) and MDMA (ecstasy) use and depressive symptoms in secondary school students. J Epidemiol Commun Health. 2012;66(11):990-4.

28. Eslami-Shahrbabaki M, Fekrat A, Mazhari S. A study of the prevalence of psychiatric disorders in patients with methamphetamine-induced psychosis. Addict Health. 2015;7(1-2):37-42. 
29. Shakeri J, Azimi M, Rezayi M, Abdoli N, GhasemiSR. The evaluation of demographics, behavioral and psychiatric characteristics of methamphetamine abusers in detoxification and addiction control clinics related to Kermanshah University of Medical Sciences. Iran J Psychiatry Clin Psychol. 2010;16(3):305-6.

30. Compton III WM, Cottler LB, Jacobs JL, Ben-Abdallah A, Spitznagel EL. The role of psychiatric disorders in predicting drug dependence treatment outcomes. Am J Psychiatry. 2003;160(5):890-5.

31. McKetin R, Voce A, Burns R. Research into methamphetamine use in the Australian Capital Territory. Perth Australia: National Drug Res Institute. 2017.

32. Bungay V, Malchy L, Buxton JA, Johnson J, MacPherson D, Rosenfeld T. Life with jib: A snapshot of street youth's use of crystal methamphetamine. Addict Res Theory. 2006;14(3):235-51.

33. Hosseinifard SM, Ahmadian A, Smaeelifar N. The Synergistic (MARATHON) Effect of combined methamphetamine with sexual stimulant drugs on increasing the likelihood of high-risk sexual behaviors. Addict Health. 2014;6(3-4):112.

34. Lim SH, Akbar M, Wickersham JA, Kamarulzaman A, Altice FL. The management of methamphetamine use in sexual settings among men who have sex with men in Malaysia. Int $J$ Drug Policy. 2018; 55:256-62.

35. Lebni JY, Ziapour A, Qorbani M, Khosravi B, Mirzaei A, Safari O, et al. Explaining the causes of crystal addiction in Tehran: a qualitative approach. J Public Health. 2019:1-7.

36. Speziale HS, Streubert HJ, Carpenter DR. Qualitative research in nursing: Advancing the humanistic imperative: Lippincott Williams \& Wilkins; 2011.

37. Munhall P. A phenomenological method. PL Munhall (Ed), Nurs Res: A qualitative perspective. 2007;4:145-210.

38. Graneheim UH, Lundman B. Qualitative content analysis in nursing research: concepts, procedures and measures to achieve trustworthiness. Nurse Educ Today. 2004;24(2):105-12.

39. Marshall MN. Sampling for qualitative research. Family Pract. 1996;13(6):522-6.

40. Lincoln YS, Guba E. Naturalistic Inquiry London. England: Sage Publications. 1985.

41. Kennedy KM. The Relapse Cycles of Female Methamphetamine Users. 2015.

42. Bostani D, Karamizadeh A. Condition and strategy of glass consumption among addicted women (case study: Kerman city). Women Develop Politic. 2017;15(1):1-20.

43. Moheb Ali H, Qasam A, Mardani S. Measurement of the motivations leading to the use of industrial opiates (case study of caretakers in Qazvin). J Qazvin Law Enforce Q. 2016;5(7):114-33.

44. Siah Jani L, Orki M, Zare H. Methamphetamine use time (glass) and persistent attention deficit disorders in methamphetamine abusers. J Drug Addict Res. 2014; 27:53-66.

45. De Silva DA, Wong MC, Lee MP, Chen CL-H, Chang HM. Amphetamine-associated ischemic stroke: clinical presentation and proposed pathogenesis. J Stroke Cerebrovas Diseas. 2007;16(4):185-6.

46. Cooper HL, Brady JE, Ciccarone D, Tempalski B, Gostnell K, Friedman SR. Nationwide increase in the number of hospitalizations for illicit injection drug use-related infective endocarditis. Clin Infect 
Diseas. 2007;45(9):1200-3.

47. Hasan AA, Ciancio S. Relationship between amphetamine ingestion and gingival enlargement. Pediatr Dentist. 2004;26(5):396-400.

48. Rhodus N, Little J. Methamphetamine abuse and" meth mouth". North Dentist. 2005;84(5):29, 31, 3-7.

49. Line, N. Evaluation anger control training on individual and social adaptation of addicts. J Consul Develipm. 2010;44(77):34-50.

50. Ghorbani M, Kazemi H, Ghorbani T. Comparing irrational beliefs in patients with crystal abuse disorder and ordinary people. Knowled Res Appl Psychology Autum. 2011;12(3):32-7.

51. Neale A, Abraham S, Russell J. “Ice” use and eating disorders: A report of three cases. Int J Eating Disor. 2009;42(2):188-91.

52. Wilkins C, Reilly J, Rose E, Roy D, Pledger M, Lee A. The Socio-Economic impact of amphetamine type stimulants in New Zealand. Centre for Social and Health Outcomes Research and Evaluation (SHORE) Massey University, Auckland. 2004.

53. Hadland SE, Marshall BD, Kerr T, Qi J, Montaner JS, Wood E. Depressive symptoms and patterns of drug use among street youth. J Adol Health. 2011;48(6):585-90.

54. Colfax G, Vittinghoff E, Husnik MJ, McKirnan D, Buchbinder S, Koblin B, et al. Substance use and sexual risk: a participant-and episode-level analysis among a cohort of men who have sex with men. Am J Epidem. 2004;159(10):1002-12.

55. Shoptaw S, Reback CJ, Freese TE. Patient characteristics, HIV serostatus, and risk behaviors among gay and bisexual males seeking treatment for methamphetamine abuse and dependence in Los Angeles. J Addict Diseas. 2001;21(1):91-105.

56. Reback CJ, Larkins S, Shoptaw S. Changes in the meaning of sexual risk behaviors among gay and bisexual male methamphetamine abusers before and after drug treatment. AIDS Behav. 2004;8(1):87-98.

57. Semple SJ, Patterson TL, Grant I. The context of sexual risk behavior among heterosexual methamphetamine users. Addict Behav. 2004;29(4):807-10.

58. Maxwell JC. Emerging research on methamphetamine. Current Opin Psychiatry. 2005;18(3):235-42.

59. Lundqvist T. Cognitive consequences of cannabis use: comparison with abuse of stimulants and heroin with regard to attention, memory and executive functions. Pharmacol Biochem Behav. 2005;81(2):319-30.

60. Izawa J-i, Yamanashi K, Asakura T, Misu Y, Goshima Y. Differential effects of methamphetamine and cocaine on behavior and extracellular levels of dopamine and 3, 4-dihydroxyphenylalanine in the nucleus accumbens of conscious rats. European J Pharmacol. 2006;549(1-3):84-90.

61. Ernst T, Chang L, Leonido-Yee M, Speck O. Evidence for long-term neurotoxicity associated with methamphetamine abuse: A 1H MRS study. Neurology. 2000;54(6):1344-9.

62. Gard C. Methamphetamine: Speeding Toward Psychosis. Current Health. 2004;30(5):25- 
63. Werb D, Kerr T, Zhang R, Montaner JS, Wood E. Methamphetamine use and malnutrition among street-involved youth. Harm Reduct J. 2010;7(1):5.

64. He J, Xie Y, Tao J, Su H, Wu W, Zou S, et al. Gender differences in socio-demographic and clinical characteristics of methamphetamine inpatients in a Chinese population. Drug Alcohol Depend. 2013;130(1-3):94-100.

65. Mansorian M, solhi $\mathrm{m}$, Dehdar T, Taghdisi MH. Hallucination experience in drug users: a qualitative study. J Iran Institut Health Sci Res. 2014;13(14):467-75.

66. Baggott MJ, Siegrist JD, Galloway GP, Robertson LC, Coyle JR, Mendelson JE. Investigating the mechanisms of hallucinogen-induced visions using 3, 4-methylenedioxyamphetamine (MDA): a randomized controlled trial in humans. PloS One. 2010;5(12): e14074.

67. Akiyama K. Longitudinal clinical course following pharmacological treatment of methamphetamine psychosis which persists after long-term abstinence. Ann New York Acad Sci. 2006;1074(1):125-34.

68. Mahoney III JJ, Hawkins RY, De La Garza II R, Kalechstein AD, Newton TF. Relationship between gender and psychotic symptoms in cocaine-dependent and methamphetamine-dependent participants. Gender Med. 2010;7(5):414-21. 